\title{
Некоторые вопросы современного расселения и административно-территориального устройства России
}

\author{
Г.И.Кадышев, ЦНИИП Минстроя РФ, Москва
}

В статье кратко изложены основные особенности формирования административно-территориального устройства и управления России в сопоставлении с аналогичным процессом во Франции. Наибольшее внимание в рассмотрении этой проблемы уделяется естественному процессу самоорганизации населения, в результате которого из первоначально малых систем расселения со своими центрами и инфраструктурой образовалась целостная поселенческая структура страны с чёткой трёхступенчатой иерархией административно-территориального деления и управления. Даётся оценка роли политических преобразований в стране после революции 1917 года и результатов волевых решений руководителей СССР относительно учреждения административно-территориальных единиц по национальному признаку. Рассматривается влияние различных факторов на складывающееся после 1991 года новое административно-территориальное устройство России. Анализируются положения Федерального закона №131-Ф3 «0б общих принципах организации местного самоуправления в Российской Федерации» в части административно-территориального деления России и полномочий муниципальных образований различного уровня. Выявлены наиболее спорные положения в существующем административно-территориальном делении и разделении полномочий различных уровней. Даны предложения по совершенствованию ряда статей Федерального закона №131-Ф3.

Ключевые слова: административно-территориальное устройство, муниципальное управление, историческая система расселения.

Some Issues of Modern Settlement and AdministrativeTerritorial Structure of Russia

G.Kadyshev, TsNIIP Minstroy of Russia

The article summarizes the main features of the formation of the administrative-territorial structure and management of Russia in comparison with a similar process in France. The greatest attention in the consideration of this problem is given to the natural process of self-organization of the population, as a result of which from the initially small settlement systems with their centers and infrastructure an integral settlement structure of the country with a clear three-level hierarchy of administrative-territorial division and management was formed. The role of political transformations in the country after the 1917 revolution and the results of strongwilled decisions of the leaders of the USSR regarding the establishment of administrative-territorial units on a national basis are estimated. The influence of various factors on the new administrative and territorial structure of Russia emerging after 1991 is considered. The article analyzes the provisions of Federal Law No. 131-FZ "0n the General Principles of the Organization of Local Self-Government in the Russian Federation" regarding the administrative-territorial division of Russia and the powers of municipal entities at variouslevels. The most controversial provisions in the existing administrative-territorial division and separation of powers of various levels are revealed. Suggestions are given for improving a number of articles of Federal Law No. 131-FZ.

Keywords: administrative-territorial structure, municipal management, historical settlement system.

Процесс становления административно-территориального устройства России в течение многовековой истории развития страны представляет большой интерес. Можно проследить закономерности и характерные особенности формирования административной системы, оценить роль населения и его самоорганизации в различные периоды, роль политических преобразований в стране и волевых решений её руководителей, сравнить российские формы административно-территориального устройства с некоторыми примерами зарубежных стран, определить влияние тех или иных факторов на складывающееся после 1991 года новое административно-территориальное устройство России.

Наибольшее внимание в рассмотрении этой проблемы уделяется естественному процессу самоорганизации населения, в результате которого из первоначально малых систем расселения со своими центрами и инфраструктурой образовалась целостная поселенческая структура страны с чёткой трёхступенчатой иерархией административно-территориального деления и управления, а также отрицательными примерами сомнительных политических решений, не выдержавших испытание временем, либо приведших к тяжёлым последствиям через десятилетия после их принятия.

Анализ истории формирования административно-территориальной организации России в дореволюционный период [1] и зарубежного опыта на примере Франции показывает первостепенную роль расселения в создании государственной системы административно-территориального устройства и выявляет общие черты [2; 3], свойственные как российской, так и французской системам административно-территори- 
альной организации, и системе управления, среди которых можно выделить следующие основные.

- Полномочия органов управления всех уровней отвечают требованию чёткого соблюдения вертикали управления, что выражается и в главенствующей роли государства в градостроительстве и строительной деятельности. Во французском законодательстве также чётко выражена вертикаль управления - от президента до мэра города (коммуны) и отражены приоритеты государственных интересов в области территориального планирования и градостроительства.

- Отсутствие исключительного положения и исключительных прав какого-либо региона (губернии) или города (даже столичного). Ни один город в дореволюционной России, как и во Франции, не обладал особым статусом в отличие от российских городов особого подчинения в период СССР и городских округов и городов - субъектов федерации в период после 1991 года.

- Все столичные, губернские, уездные города - центры тяготеющих к ним территорий, являлись составными частями этих территорий, что чётко соответствовало структуре расселения. Подобное положение можно увидеть и в административно-территориальном устройстве Франции. Так, Париж, будучи столицей государства, является департаментом и одновременно коммуной региона Иль-де-Франс.

- В административно-территориальном устройстве как России, так и Франции, территориальные единицы не выделялись по национальному признаку. В России территории с определёнными границами, имеющие в значительном количестве неправославное (нерусское) население, находились в статусе губерний и располагали обычными в таких случаях полномочиями. По такому же принципу формировались регионы (аналоги губерний) во Франции.

- Важную роль играли структуры первичной хозяйственной жизни и административно-территориальной организации - волости в России $[4 ; 5]$ и коммуны во Франции. Эти первичные единицы являлись основным «строительным материалом», из которого складывались уезды (департаменты), а затем и губернии (регионы), строилась трёхуровневая система управления. Несмотря на официальное пятиуровневое административное деление современной Франции, только коммуны, департаменты и регионы располагают органами самоуправления. Административные единицы кантон и округ не обладают органами общей администрации и выступают как территориальные объединения отдельных административных организаций. Трёхступенчатая система самоуправления во Франции функционирует сегодня в пределах трёх административных единиц: коммуна - департамент - регион.

Такое естественное объединение территорий на основе самоорганизации населения и рациональной системы управления привело к созданию устойчивого административнотерриториального устройства, способствующего успешному развитию России на протяжении двух сотен лет и процветанию Франции по сей день.
Революция 1917 года перевернула существующий порядок вещей. После падения Российской Империи, смены власти и провозглашения нового пути развития был принят ряд решений по преобразованию административно-территориального устройства государства. В 20-х годах XX века ещё сохранялась структура губерний и уездов, но система важнейшего первичного звена - волостей, была полностью разрушена и заменена многочисленными сельсоветами, фактически лишёнными какой-либо власти. Позднее, в 30-х годах, начались поиски новой административно-территориальной организации, укрупнение или дробление существовавших губерний и создание областей и районов. Но главное, что стало абсолютно новым ещё в начале 20 -х годов, - образование административно-территориальных единиц по национальному признаку. Появились национальные сельсоветы, районы, автономные области и автономные республики в составе единого государства России - Российской Федерации. Еще до подписания в 1922 году декларации о создании Союза Советских Социалистических Республик (СССР) - союза государств с правом самоопределения - были образованы государствареспублики - Украинская, Белорусская, Казахская и другие. При этом выделение национальных образований в составе союза республик производилось не столько с учётом расселения национальных сообществ, сколько на основе классового состава населения, наличия рабочего класса и развития промышленности на этих территориях. И хотя независимость республик была весьма относительной, учитывая главенствующую в руководстве страной роль коммунистической партии, такое решение изначально заключало в себе угрозу распада государства, что и доказали события конца прошлого века.

Характерным примером недальновидных действий советской власти может служить создание республики Украина в границах, не учитывающих сложившиеся этнические и национальные структуры расселения. Принятое советским правительством еще в начале 20-х годов решение о включении в состав Украины земель не только в границах, предложенных Центральной Радой, но и очень значительных по площади восточных, юго-восточных и причерноморских земель преследовало цель преодолеть национализм, развившийся в западных и центральных землях, и получить при этом поддержку русского и русскоязычного населения востока и юго-востока, тесно связанного с Россией. Как свидетельствуют последующие события почти столетнего периода, национализм не только не был преодолён, но получил особое развитие в период Великой Отечественной войны, когда была создана Украинская повстанческая армия (УПА), и проявляется в очень острой форме в настоящее время [6].

Ещё одним советским изобретением в системе административно-территориального устройства стали города [7] с особым статусом - «города общероссийского подчинения», «города областного подчинения». В советский период соблюдался принцип жёсткой вертикали управления. Но осуществлялся он не столько в соответствии с правами и полно- 
мочиями разных уровней администрации, сколько партийным руководством ВКП (б), а впоследствии КПСС, путём жёсткой, беспрекословной партийной дисциплины. И хотя подобные административные преобразования нарушали сложившуюся исторически структуру расселения, инфраструктурные связи, повседневную жизнь населения в разделённых по системе управления ранее целостных территориальных образованиях, такое деление было удобно центральным государственным и партийным властям для управления развитием отдельных наиболее важных для государства оборонных, научных и других предприятий. Для самих же обладающих высоким статусом городов это создавало особые условия развития, но одновременно вычленяло из общей структуры расселения, где исторически они являлись центральным ядром, «сердцем» устоявшихся структур расселения, а это, в свою очередь, приводило к серьёзным затруднениям в развитии и самих городов, и прилегающих к ним территорий. Ярким примером могут служить Москва и Московская область.

Распад СССР, переход на принципы капиталистического производства и развития частных хозяйственных структур оказали существенное влияние на административно-территориальное устройство. Экономическая перестройка привела к резкому снижению уровня жизни населения [8]. В этот период, после 1991 года, стали наблюдаться катастрофические явления - уход населения с освоенных территорий (прежде всего, сёл и деревень, малых городов и посёлков) и резкое изменение направленности расселения: к центру от ранее освоенных земель городов и деревень вместо существовавшего на протяжении столетий движения - от центра, для освоения новых земель и периферии. Это отразилось прежде всего в быстром разрастании нескольких крупных городов и формировании агломерационных образований. Сегодня чётко видны два следствия: опустошение ранее освоенных территорий, с одной стороны, и с другой - концентрация населения в отдельных точках. Ряд решений правительства, касающихся пространственного развития и градостроительства, скорее исходит из сложившейся тенденции к опустошению и обезлюдению ранее освоенных территорий страны, чем пытается противостоять этому разрушительному явлению в системе расселения.

До сих пор не находится объяснения передаче в 2011 году городу Москве части территорий Московской области в размере, в полтора раза превышающем существующую площадь Москвы. Это решение ещё раз демонстрирует порочность наделения отдельных городов особыми полномочиями и особым статусом, выделяющим их из общей структуры расселения. Рост численности населения столицы превышает всякие разумные пределы. В Москве на сегодняшний день сосредоточилось около 14-15 процентов населения страны, а в перспективе эта цифра на имеющейся у Москвы территории может возрасти до 30-35.

Пока по этому поводу не принято никакого законодательного решения (кроме частных законодательных положений), а конкретные управленческие или хозяйственные действия затрагивают только отдельные вопросы и никак не меняют эту катастрофичную для страны ситуацию в целом.

Новое законодательство по административно-территориальному устройству после 1991 года в основном сохранило структуру региональных территорий, областей, краёв, республик с какими-то небольшими изменениями границ или наименований. Главное достижение - с 1993 года была инициирована работа по законодательному обеспечению организации местного самоуправления. В 2003 году вступил В силу Федеральный закон №131-Ф3 «0б общих принципах организации местного самоуправления в Российской Федерации».

Внимательное рассмотрение этого закона позволяет высказать ряд соображений о его несовершенстве по некоторым позициям. В нём явно прослеживается определённая инерция, связанная с переходом от прежней общегосударственной системы управления к системе управления муниципальной и соответственному административно-территориальному устройству. Можно выразить также сожаление по поводу того, что создаваемая система административно-территориального устройства вырабатывалась как бы с чистого листа, без опоры на опыт дореволюционной России и опыт зарубежных стран.

В данном законе отмечается определённая пролонгация положений, существовавших в системе управления в советский период: выделение городов республиканского, регионального (областного) и районного значения со своими органами управления и использование этих структур в современном законодательстве, но в новом прочтении в виде городских округов (также городов, выделенных из общей системы районов или областей). В другой, обновлённой редакции 2017 года, городские округа оказались уже в совершенно другом качестве - в виде дублёров муниципальных районов, способных полностью вытеснить муниципальные районы как единицы территориальной структуры и как единицы муниципального образования. Это говорит об отсутствии научно обоснованного подхода, критериев и принципов в определении иерархии единиц местного самоуправления. Такая административная единица, ранее называвшаяся уездом (районом) и являвшаяся основой структуры расселения, играла важную роль в жизнедеятельности населения. Можно еще раз вспомнить, что значение этой структуры в системе административно-территориального устройства России всегда было очень велико. В России эта единица управления упоминается с XII века и окончательно закрепилась в конце XVIII века. А во Франции по реформе в период Французской революции в течение почти ста пятидесяти лет подобная единица - департамент - вообще была основой административно-территориального устройства

Первоначально структура административно-территориального устройства на основе закона №131-Ф3 складывалась из субъекта Российской Федерации, муниципального района, городских и сельских поселений, составляющих территорию района, а городской округ (в формулировках 2003 года) 
являлся структурой, по территории сходной с городским поселением, но обладающим некоторыми государственными полномочиями, как муниципальный район, что делало его сходным с ранее существовавшим городом областного подчинения. К этому можно еще добавить, что единицы местного самоуправления законодательно не были признаны единицами административно-территориального устройства.

С учётом внесённых в 2014 и 2017 годах в закон №131-Ф3 2003 года дополнений и поправок неопределённость роли городского округа проявилась ещё и в новом качестве, так как его внутренняя структура представляет собой уже не город с прилегающей территорией, а территорию по площади и составу населённых пунктов равную муниципальному району, а по полномочиям значительно его превосходящую. Эта неопределённость усугубляется тем, что такое образование может полностью заменить муниципальный район, а при наличии других соседствующих с городским округом муниципальных районов появляются две единицы муниципальной структуры одного уровня, во многом дублирующие друг друга, а в случае занятия городским округом части территории муниципального района его положение в этой системе становится совершенно неясным.

В вопросах, связанных с ролью городских округов и их сходством с муниципальными районами по ряду факторов, в конечном итоге необходимо разобраться на законодательном уровне. Этой исторической административно-территориальной структуре (ранее уезд, дистрикт - в России, или департамент - во Франции) должна соответствовать только одна административно-территориальная единица.

Рассмотрение плана административно-территориального устройства Московской области говорит об активном утверждении городских округов как важнейшей составляющей структуры муниципальных образований.

В качестве городских округов из некоторых муниципальных районов выделились отдельные города: Электросталь, Черноголовка, Ивантеевка, Королев, Дубна, Бронницы, Электрогорск, Дзержинский, Котельники, Звенигород, Жуковский, Красногорск, Лобня, Рошаль, Лыткарино, Протвино, Пущино, Реутов, Фрязино, Долгопрудный, Красноармейск.

В статусе муниципальных районов на 1 января 2019 года существовали только 16 районов: Волоколамский, Воскресенский, Ленинский, Лотошинский, Одинцовский, Пушкинский, Раменский, Сергиево-Посадский, Серпуховский, Солнечногорский, Шаховской а на 6 мая 2019 года - уже не 16 муниципальных районов, а только 7. К сентябрю 2019 года все муниципальные районы заменены городскими округами. Кроме того, в области существуют ещё пять населённых

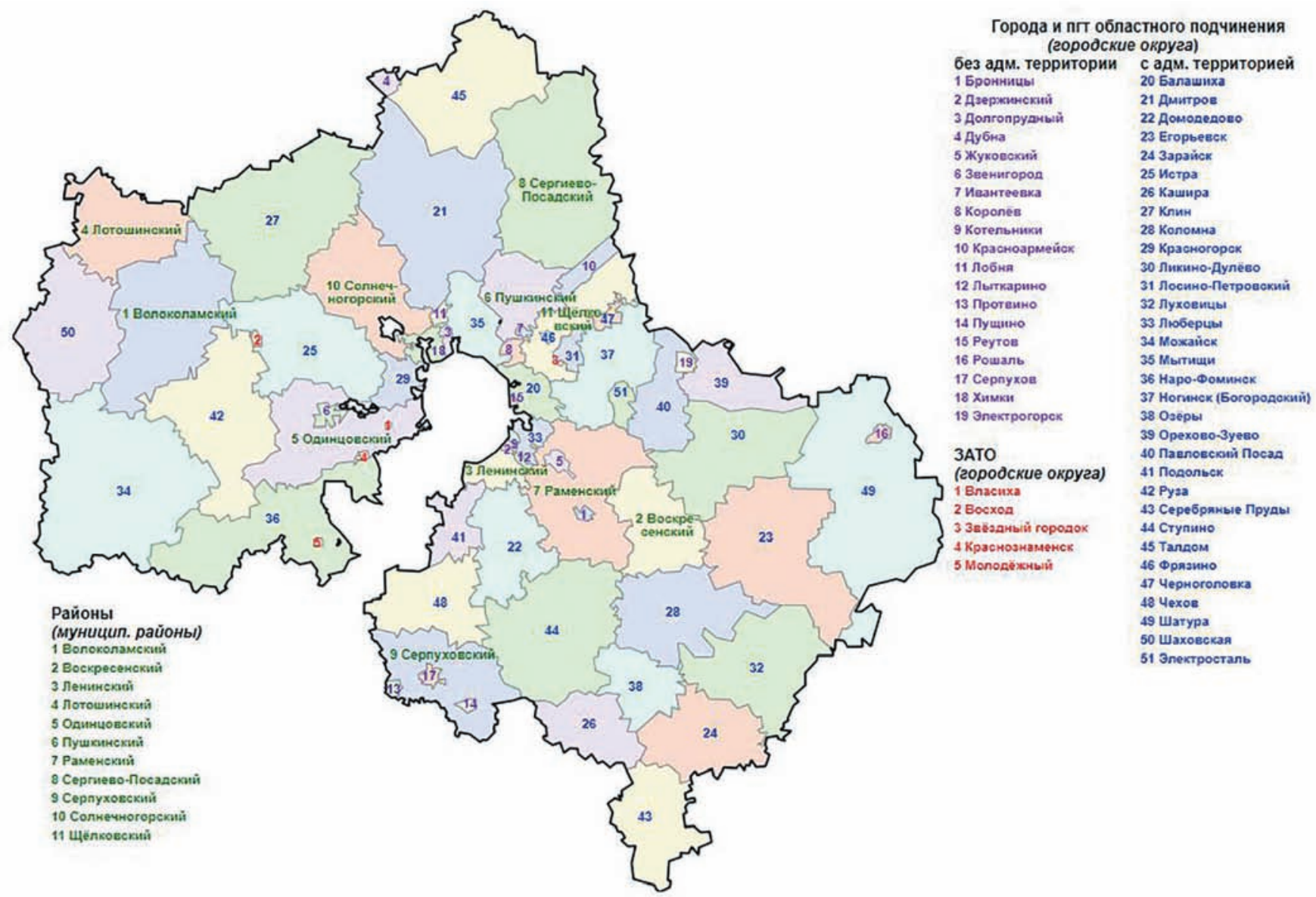

Puc. 1. Административно-территориальное деление Московкой области. 2018 год (источник: https://fb.ru/misc/i/ gallery/48794/2943064.jpg) 

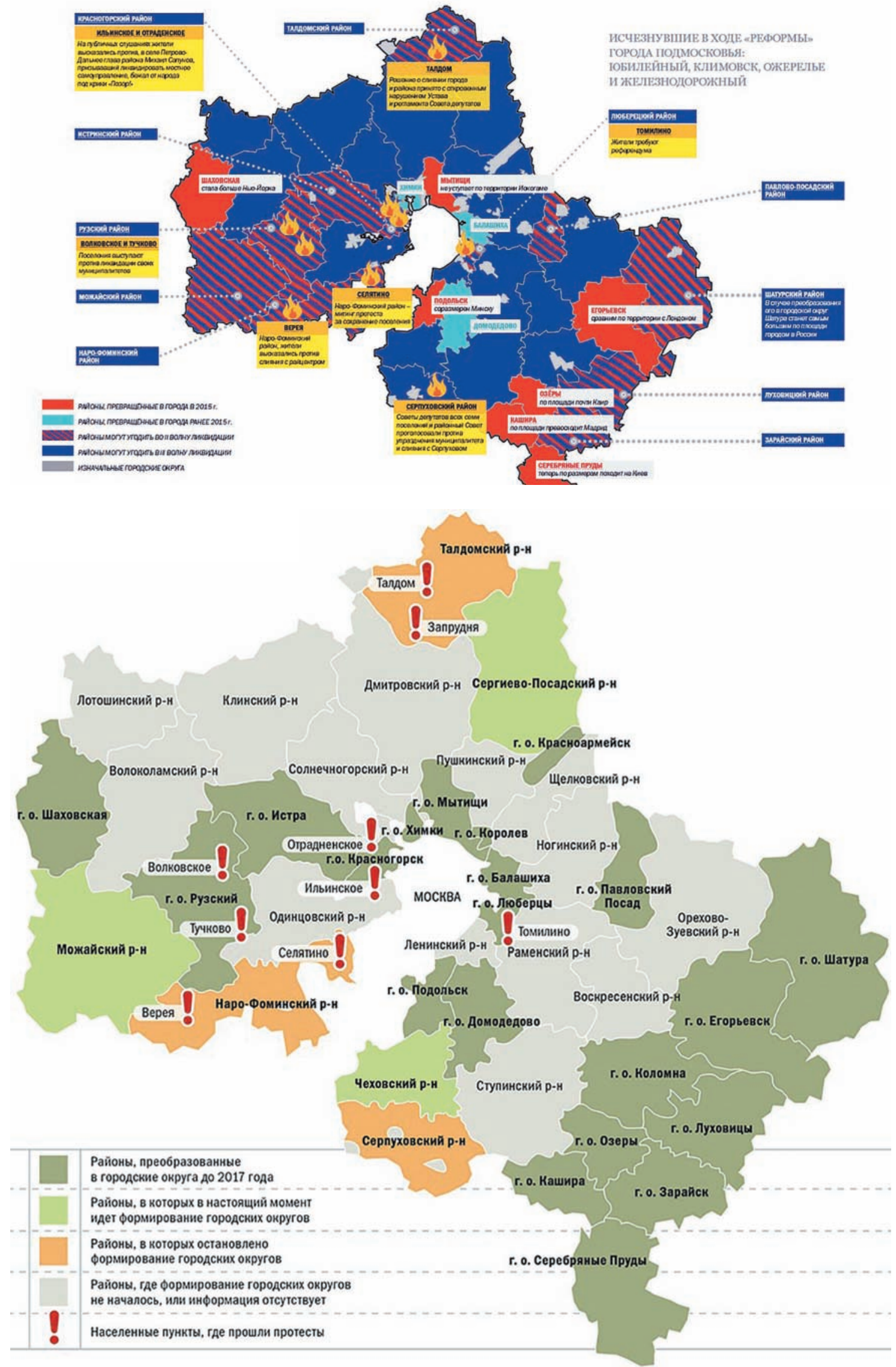

Б

Puc. 2. Административно-территориальная реформа Московской области: A - 2015-2016 годы (ucmoчник: https://pbs.twimg. com/media/DRCC6g7XUAE8zkk.jpg); Б-2017-2019 годы (источник: https://pp.vk.me/c836328/v836328026/17aac/J4VZRg1H-dc.jpg) 
пунктов - закрытых административно-территориальных образований (ЗАТ0), которые также имеют статус городских округов (рис. 1, 2, 3).

Интересно отметить, что почти все города, являющиеся сегодня центрами городских округов, имели в советское время статус городов областного подчинения и только некоторые приобрели этот статус в девяностые годы. Это ещё раз показывает преемственность сегодняшней административно-территориальной организации от существовавшей при советской власти.

Если посмотреть законодательство, то, например, в Московской области по закону Московской области №11/201303 образована чётко выраженная двухуровневая система административно-территориального устройства подобно той, что существовала до 1991 года. Административно-территориальными единицами являются:

- районы;

- города и посёлки городского типа областного подчинения с административной территорией и без неё;

- закрытые административно-территориальные образования.

В структуре управления муниципальных образований районам соответствуют муниципальные районы, сельские и городские поселения в составе муниципального района; городам и посёлкам городского типа областного подчинения «как с территорией, так и без неё» (непонятно, как может административно-территориальная единица быть без территории) - соответствуют городские округа, а также закрытые административно-территориальные образования (эти данные соответствуют только периоду, когда городские округа ещё не вытеснили полностью муниципальные районы).

Здесь можно задать очень простой вопрос: почему органы региональной власти областей, краёв или республик не считают возможным признавать законными и единственными единицами административно-территориального устройства единицы местного самоуправления? Ведь они обладают и территорией, и населением, и органами управления, что установлено законом №131-Ф3.

Проблемы появились и при реализации системы управления. Проявилась возможность существования на одной и той же территории двух уровней власти: государственной и муниципальной в виде образования на той или другой территории государственных органов управления. При этом нет ясности, как это соотносится с передачей муниципальным районам и городским округам отдельных государственных полномочий. Внедрение в современных условиях развития страны в муниципальные структуры государственных органов управления можно объяснить несколькими причинами:

- во-первых, определёнными ранее существовавшими формами управления территориями;

- во-вторых, недоверием органов государственной власти к возможности органами местного самоуправления выполнять задачи развития территорий с учётом всех их особенностей: наличия особо важных для страны промышленных или научных объектов, особых природных условий, наличия или недостатка материальных ресурсов, положения в приграничных территориях и др.;

- в-третьих, видимо, положения Федерального закона № 131-Ф3 о выполнении муниципальными районами и городскими округами отдельных государственных полномочий считаются государственными органами субъекта Российской Федерации недостаточными и не способными обеспечить выполнение задач государственной значимости.

Изложенные вопросы к содержанию Федерального закона № 131-Ф3 дают основания выразить уверенность в необходимости доработки или переработки основополагающих статей закона. По мнению автора, необходимо повысить роль муниципального образования под названием «муниципальный район» как структуры, складывающейся в процессе расселения и удовлетворяющей интересы населения на своей территории по многим функциям, которые не входят ни в функции областей, то есть структуры более высокого уровня управления, ни в функции сельских и городских поселений, то есть уровня повседневных интересов. При этом полномочия муниципального района должны обеспечивать комплексное развитие всех элементов инженерной и социальной инфраструктуры на всей его территории, включая ряд видов инфраструктуры и на территории населённых пунктов.

Учитывая, что на практике сложилось два образования одного уровня с компетенциями по выполнению определённых государственных полномочий и равных по площади, каждый из которых с некоторой условностью может быть рассмотрен как преемник ранее существовавших районов и уездов, возникает необходимость создания одной муниципальной единицы данного уровня, но сочетающей в своих полномочиях то, что было рационально в каждом из этих двух упомянутых муниципальных образований. Эта единица не обязательно должна называться «муниципальный район». Вполне возможно, например, использовать историческое название «уезд».

Никакими исключительными статусами любой город обладать не должен. Это можно отнести не только к городам внутри регионов, но и к столичным городам субъектов Федерации, в настоящее время имеющим свои особые права, приравнивающие их в системе управления к областям, краям, республикам и одновременно лишающие их в системе управления роли центров исторически складывающихся систем расселения.

Особенности развития каких-то городов могут быть определены особыми государственными полномочиями, которыми наделялись и муниципальный район, и городской округ по закону №131-Ф3 ${ }^{1}$. Если учесть и российский дореволюционный и зарубежный опыт, то выделение Москвы и Санкт-Петербурга из общей системы, тоже вызывает вопрос. Это отрывает их от

${ }^{1}$ Федеральный закон от 06.10.2003 №131-Ф3 «0б общих принципах организации местного самоуправления в Российской Федерации» (с изменениями и дополнениями на 2019 год). - М. : Актуальное законодательство, 000 «Издательство ЭКСМ0», 2019. 
структуры расселения, в которой они существуют, и создаёт проблемы в развитии как для собственно города, так и для региона.

Должны быть уточнены полномочия и названия низовых муниципальных образований, которые сейчас в составе муниципального района называются городскими и сельскими поселениями, а в городском округе - внутригородскими районами. Сохраниться в новых уточнённых границах и полномочиях название «поселение» или «внутригородской район» или будет присвоено какое-то другое название, например, историческое название «волость» - это вопросы доработки закона. Низовую единицу уезда (город) наравне с современным термином «городское поселение» целесообразно именовать просто «город».

Уровни управления в структуре государственных и муниципальных образований должны быть чётко определены:

- субъект Федерации,

- муниципальный район (уезд, район и др.),

- низовое муниципальное образование (волость, городпосёлок).

Необходимо также в числе важнейших законодательных актов принятие закона Российской Федерации об административно-территориальном устройстве.

Сказанное выше еще раз свидетельствует о том, что общегуманитарные соображения, определённые закономерности, сформулированные градостроительной наукой, должны стать приоритетными в процессе разработки законодательных документов.

\section{Лuтература}

1. История России с древнейших времен - начало XXI века / Под редакцией А.Н. Сахарова. - М. : АСТ-Пресс школа, 2017.

2. Ферро, М. История Франции / М. Ферро; пер. с фр. - М. : Весь мир, 2015. - 832 с.

3. Гримо, Ж. Организация административной власти во Франции / Ж. Гримо. - М. : Изд. группа «Интратэк-Р», 1994. -261 c.

4. Волости и важнейшие селения Европейской России : по данным обследования, произведённого стат. учреждениями Министерства внутренних дел. Вып. 2. «Губернии Московской промышленной области» / Центральный статистический комитет. - СПб, 1886.
5. Справочник по административно-территориальному делению Московской губернии (1917-1929) / Гл. арх. упр. при Совете министров СССР и др. - М., 1980 . - 556 с.

6. Медведев, А.А. Русский путь. Подлинная история русского и украинского народа / А.А. Медведев. - М. : Эксмо, 2015. - 510 c.

7. Любовный, В.Я. Города России: альтернативы развития и управления / В.Я. Любовный. - М. : Экон-информ, 2013. - 614 с.

8. Школьник, Ю.К. История России: Полная энциклопедия от древнейших времен до начала XX века / Ю.К. Школьник. - М. : Эксмо, 2017 . - 256 с.

\section{References}

1. In A.N. Sakharov (ed.) Istoriya Rossii s drevneishikh vremen - nachalo XXI veka [The history of Russia from ancient times to the beginning of the XXI century]. Moscow, AST-Press shkola Publ., 2017.

2. Ferro, M. Istoriya Frantsii [History of France]. Moscow, Ves' mir Publ., 2015, 832 p.

3. Grimo, Zh. Organizatsiya administrativnoi vlasti vo Frantsii [Administrative Authority in France]. Moscow, Intratek-R Publ., 1994, 261 p.

4. Volosti i vazhneishie seleniya Evropeiskoi Rossii : Po dannym obsledovaniya, proizvedennogo stat. uchrezhdeniyami M-va vn. del [Volosts and the most important villages of European Russia: according to a survey conducted by stat. institutions of the Ministry of the Interior], Vyp. 2. Gubernii Moskovskoi promyshlennoi oblasti [Is. 2. Provinces of the Moscow Industrial Region]. St. Petersburg, 1886.

5. Spravochnik po administrativno-territorial'nomu deleniyu Moskovskoi gubernii (1917-1929) [Directory of administrativeterritorial division of the Moscow province (1917-1929)]. Moscow, 1980, $556 \mathrm{p}$.

6. Medvedev, A.A. Russkii put'. Podlinnaya istoriya russkogo i ukrainskogo naroda [Russian way. The true history of the Russian and Ukrainian people]. Moscow, Eksmo Publ., 2015, 510 p.

7. Lyubovnyi, V.Ya. Goroda Rossii: al'ternativy razvitiya $i$ upravleniya [Cities of Russia: Alternatives to Development and Management]. Moscow, Ekon-inform Publ., 2013, 614 p.

8. Shkol'nik, Yu.K. Istoriya Rossii: Polnaya entsiklopediya ot drevneishikh vremen do nachala XX veka [History of Russia: A complete encyclopedia from ancient times to the beginning of the twentieth century]. Moscow, Eksmo Publ., 2017, 256 p.

Кадышев Георгий Иванович (Москва). Член-коррепсондент РААСН. Старший научный сотрудник ФГБУ «ЦНИИП Минстроя России» (119331, Москва, проспект Вернадского, 29. цНИИП Минстроя России). Эл.почта: grado@raasn.ru.

Kadyshev Georgy Ivanovich (Moscow). Corresponding Member of RAACS. Senior Researcher at the Institute for Research and Design of the Ministry of Construction and Housing and Communal Services of Russia (29 Vernadskogo avenue, Moscow, 119331. TsNIIP).E-mail: grado@raasn.ru. 